\title{
The Impact of the Flipped Learning Model on the Development of Kindergarten Pre-service Teachers' Self-Directed Learning Skills in Saudi Arabia
}

\author{
Badiah N. M. Alnasib ${ }^{1, *}$, Asma M. H. Ali ${ }^{2}$ \\ ${ }^{1}$ Department of Curriculum and Teaching Methods, College of Education, King Faisal University, Saudi Arabia \\ ${ }^{2}$ Department of Kindergarten, College of Education, King Faisal University, Saudi Arabia
}

Received July 10, 2020; Revised August 20, 2020; Accepted September 11, 2020

\section{Cite This Paper in the following Citation Styles}

(a): [1] Badiah N. M. Alnasib, Asma M. H. Ali , "The Impact of the Flipped Learning Model on the Development of Kindergarten Pre-service Teachers' Self-Directed Learning Skills in Saudi Arabia," Universal Journal of Educational Research, Vol. 8, No. 11, pp. 5271 - 5280, 2020. DOI: 10.13189/ujer.2020.081128.

(b): Badiah N. M. Alnasib, Asma M. H. Ali (2020). The Impact of the Flipped Learning Model on the Development of Kindergarten Pre-service Teachers' Self-Directed Learning Skills in Saudi Arabia. Universal Journal of Educational Research, 8(11), 5271 - 5280. DOI: 10.13189/ujer.2020.081128.

Copyright $₫ 2020$ by authors, all rights reserved. Authors agree that this article remains permanently open access under the terms of the Creative Commons Attribution License 4.0 International License

\begin{abstract}
Self-directed learning has been recognized as one of the new pedagogical approaches of the 21st century. Many studies evidence the critical role of the flipped learning model in enhancing students' self-directed learning skills. This study aimed at examining the impact of the application of the flipped learning model on prompting pre-service teachers' self-directed learning skills at the Kindergarten Department of the College of Education at King Faisal University in Saudi Arabia. A quasi-experimental design with one group was implemented. A purposeful sample of forty-three female student teachers who enrolled in the "Introduction to Kindergarten" course participated in the study. Data were gathered using a 44-item questionnaire that was distributed pre- and post-flipped learning classes. The results indicated the effectiveness of flipped learning pedagogy on the development of student teachers' self-directed learning skills. The study sample showed a statistically significant higher mean level of self-directed learning $(4.51 \pm 0.13)$ compared to their score before the flipped learning classes $(3.13 \pm 0.25)$. The study's results confirm the conclusion of related literature concerning the positive impact of practicing flipped learning pedagogy on developing learners' self-directed learning skills. Furthermore, it is in line with the call for the integration of non-traditional teaching strategies, e.g., flipped learning pedagogy, in Saudi higher education, advocating students' self-directed
\end{abstract}

learning and independent learning. Thus, there is a need for encouraging teacher educators to integrate flipped learning into their teaching practice.

Keywords Self-directed Learning, Flipped Learning, Kindergarten, Pre-service Teachers, Higher Education, Active Learning

\section{Introduction}

\subsection{Background}

Since the early 20th century, self-directed learning (SDL) has gained remarkable attention amongst scholars in the adult education field, as it creates active learners who can survive best in this new and dynamic world [1]. Knowles [2] claimed that there is persuasive evidence that proactive learners who take the initiative in their learning process learn more and better than reactive learners who wait to be taught by their instructors. Jiusto and Dibiasio [3] claimed that traditional teaching practices, which is a common approach in most of higher education institutions, may not efficiently stimulate students' SDL. Therefore, shifting from teacher-centered classes to student-centered classes is a requirement [4], and new forms of teaching practices for 
the new generations have to be developed [5]. Amongst several efforts to meet these new learning and higher quality teaching standards, flipped learning (FL) pedagogy has emerged as an alternative model [6,7] that may promote the characteristics requisite for students to be successful lifelong learners [8]. FL is a pedagogical pattern where the homework elements and the typical lectures of a course are inverted. It reverses traditional teaching methods, moving homework into the classroom and delivering instruction online outside of class [9].

Some Saudi scholars claim that Saudi students do not want to take responsibility for their learning $[10,11]$. Students prefer to place the responsibility for their education on the shoulders of their instructors [10]. As teacher educators in the teacher preparation program at King Faisal University (KFU), we also noticed that students enrolled in the Kindergarten Department lack the ability to direct their learning. This claim was also a subject of debate amongst other educators in the department. This argument raised some questions, e.g.: Have we assisted our students to be self-directed learners? Do our teaching practices enhance our students' SDL skills? In this vein, Shaalan[12] argued that Saudi classroom culture does not depend on SDL as students are required to absorb information and then recall it in written exams to prove their understanding. Traditional teaching significantly controls the educational process in most Saudi higher education institutions [10,12-15]. Alwasal and Alhadlaq[10] suggested that when active learning becomes the basis of our teaching, students will become more motivated to take responsibility for their education. Thus, this study focused on examining the effect of FL as an active teaching pedagogy in enhancing students' SDL skills.

\subsection{Research Gap}

According to the 2015 annual report of the National Center for Academic Accreditation and Assessment (NCAAA)[16], Saudi higher education institutions are required to adopt non-traditional teaching strategies, with a focus on developing learners, independent learning and SDL. This emphasis might have arisen as a reaction to criticism directed at Saudi university graduates who lack knowledge and skill levels compared to their counterparts [17]. Accordingly, in the Kingdom of Saudi Arabia (KSA), SDL has become a subject of investigation mostly in the field of medical [18-20] and English language studies $[11,12]$. Most of these studies were descriptive, and their focus was mostly on examining Saudi students' readiness for SDL $[18,19,21]$. Few empirical research studies, such as Khodary's study [11], showed an interest in promoting Saudi students' SDL skills. Research related to SDL skills with the FL model is still in an early stage of development in KSA, e.g., AlHarbi[22]. There are few to no studies on the impact of the FL model on promoting pre-service teachers' SDL skills. Furthermore, few to no studies exist about the applications of FL on kindergarten pre-service teacher programs. To fill the research gap, the researchers carried out this study to examine the effectiveness of the FL model on students' SDL skills. Thus, the study examined two concepts: SDL and FL.

\subsection{Literature Review}

\subsubsection{Self-directed Learning}

SDL has become an essential skill for students who want to be proactive in the creation and interpretation of knowledge [23]. SDL plays a critical role in preparing college students for post-graduate life [24]. Therefore, higher education institutions and schools have encouraged their educators to support such a form of learning, whether outside or inside the classroom [12,25]. According to Kaufman[26], SDL is based on the theory that learners are qualified to control and monitor what and how they learn effectively.

Knowles [2] described SDL as an approach in which learners take the initiative with or without the assistance of educators or instructors. They can formulate learning goals, diagnose and identify their learning needs, identify human and material learning resources, select and apply adequate strategies for learning, and evaluate learning outcomes [25]. This is similar to Zainuddin and Perera's[6] point of view that SDL is a style of learning in which individuals recognize their learning needs, identify their goals and purposes, select and use adequate strategies, and evaluate the outcomes of their learning. Rutkowski et al.[5] outlined that in SDL, the learners take the initiative and accept accountability for what takes place. Learners "select, manage and assess their learning activities, which can be pursued at any time, in any place, through any means” (pp. 2-3). Indeed, SDL is a student-oriented class where students define learning's main issues and solve problems related to the real world [6]. Consequently, the educator's role shifts to that of being a facilitator of learning. They direct, guide, observe, lead, inspire wherever necessary, assess, and provide clear feedback to assist students in building their knowledge [12,27].

Studies in SDL learning confirmed its positive effect on academic performance, creativity, aspiration, curiosity, and life satisfaction [28]. SDL, furthermore, enables students to collaborate with classmates and solve problems independently with no or limited guidance from the educator [25]. This claim is in agreement with Garrison's[29] conclusion that SDL increased students' ability to work collaboratively with peers, their self-efficacy and motivation, and their intrinsic ability to work autonomously and to solve problems independently. Despite the documented advantages of SDL, some scholars were uncertain about students' SDL abilities. Hence, some related issues have emerged. For example, Kicken[30] and his colleagues stated that students are often faced with challenges and difficulties in directing their learning 
processes in on-demand education. Levett-Jones[31] argued that instructors often share the incorrect point of view that claimed students could simply develop SDL skills or that they already have SDL skills. In these regards, we argue that even if students have SDL skills, instructors cannot ensure their ability to apply those skills unless they engaged them in processes that allow them to experience their SDL skills. Borich[32] suggested that an educator can guide a student to be a self-directed learner when they design class activities and materials in a way that can enhance an independent structure of understanding. Developing SDL learners requires a teaching technique that offers students more opportunities to take more control of their learning, such as FL [33]. In this context, Rutkowski et al.[5] claimed that a FL environment might have a positive effect on learners' SDL abilities.

\subsubsection{Flipped Learning}

FL has become a modern form of pedagogy in various education institutes throughout the world [34,35] and particularly in higher education institutions [25]. FL is mostly viewed as a re-ordering of the teaching process in terms of which lessons, which are normally provided in class, are given as homework, and coursework, which is normally assigned as homework, is done in class as learning activities [36-39]. FL is also called reversed or inverted pedagogy, where the teaching is reversed and the learning is inverted. Students are required to do pre-class study by reviewing the learning materials at home; and then they engage in in-class activities [40]. This general point of view is rejected by Bishop and Verleger[41]. They stated that this explanation justifies the use of the terminology "flipped" or "inverted." However, it does not provide an adequate description of the application "of what researchers are calling the flipped classroom” (p. 4).

Bishop and Verleger[41] described a flipped classroom as an educational style that consists of two parts: direct computer-based individual instruction outside the classroom, and interactive group learning activities inside the classroom. In their definition, they emphasize the use of technology as an essential component of the FL model. In the same vein, Bergmann and Sams[36] and Roehl et al.[42] claimed that practicing FL pedagogy requires the implementation of technology to support students' learning process, in particular outside of the classroom context. This includes video recordings, voice recordings, films, videos with voiceover, screen-capture software, and visual aids with instructions $[36,42]$. Hence, class time is inverted for effective learning, e.g., practical applications and problem-solving, and there is more emphasis on learner-centered classes [43].
Mohamed and Lamia[39] argue that practicing FL pedagogy allows students to learn content materials in any place and at any time. Thus, class time can be used with the instructor to solve problems by using knowledge gained from online reading material and video lessons. Roehl et al.[42] highlighted improved connection and communication with students, increased student engagement, differentiated instruction, a deeper discussion of content, stronger collaboration skills, and creative freedom for faculty as the fundamental justifications for the move to FL pedagogy [44].

Evidence indicates that the value of FL is not limited to a specific curriculum, certain groups of learners, or a particular content area [36]. Students could achieve some indirect educational outcomes from practicing FL pedagogy. In this respect, Roehl and his colleagues [42] suggest that FL could provide new directions to improve students' higher-order thinking skills, critical thinking, and creativity. Similarly, Munir et al.[34] found that a flipped classroom contributed to the development of students' learning and critical analysis skills. Furthermore, FL could develop students' communication skills, change their learning habits, create more independent learners [35], and increase students' collaboration abilities [4]. In a higher education context, evidence from research studies revealed that FL has a great potential to enhance students' engagement in courses [43] and to improve their self-efficacy skills [45], academic achievement, motivation, and creativity [46]. Regarding SDL, Lee and Kim[47] concluded that FL had contributed to the improvement of student academic achievement and SDL. This conclusion is in agreement with Zainuddin et al.'s[25] as well as Zainuddin and Perera's[6] studies that indicated the value of flipped-class instruction for promoting students' SDL skills. However, great attention should be given to the existing learning culture as well as the mechanism of applying flipped learning pedagogy to accomplish the desired goals. For example, Sever et al.'s [48], study results revealed that flipped learning had a negative attitude towards the scientific research methods course and scientific research. The researchers attributed this to the existing learning culture.

\subsubsection{Theoretical Framework}

The theoretical framework of this study is adopted from Zainuddin et al.'s[25] "conceptual framework of self-directed learning in the EFL flipped class pedagogy" that we found to be closely related to the aim of the current study. However, we added one detail ie,. an evaluation of each FL session was required (See Figure 1). 


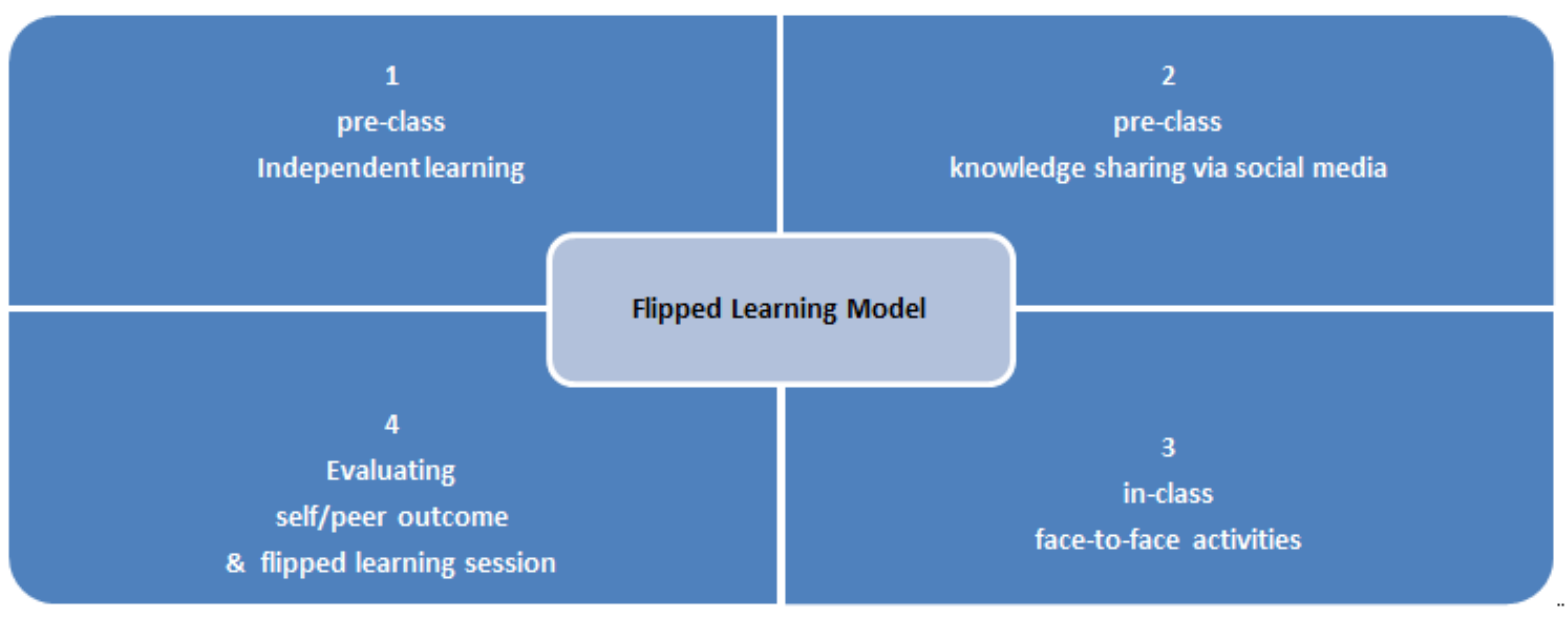

Figure 1. A framework of self-directed learning in a flipped learning class

\section{Materials and Methods}

\subsection{Study Questions and Context}

\subsubsection{Study Questions}

One research question guided this study: Is there a significant difference in students' pre-post scores in terms of SDL skills in a FL class?

\subsubsection{Study Context}

This study was conducted in the College of Education at KFU, a public Saudi university. The college is gender-separated; hence, due to cultural consideration as well as the nature of the study, it was done in female departments at the undergraduate level. The females' departments involve four main subject areas, namely, Special Education, Art Education, Education Technologies, and Kindergarten. The study took place in the first semester of the 2019/2020 academic year. It was conducted in a Kindergarten department that was easy for the researchers to access [49]. The FL model was employed to teach the "Introduction to Kindergarten" course, which is taught by one of the researchers. More than 350 students may register for the course, and they are usually divided into groups, with each group having between 50 and 60 students. One group was involved in the study.

\subsection{Design of the Study, Sample, and Sampling}

A one-group quasi-experimental design was implemented. The researchers applied this technique as a random assignment of classrooms or a random selection of students that was not quite practical [49] in this study. Furthermore, to facilitate and ensure control of factors affect this experiment. The sample consisted of 43 undergraduate students majoring in the Kindergarten Department. As mentioned above, they were one of the groups enrolled in the "Introduction to Kindergarten" course. A non-randomized purposive sampling technique was used to allow the researchers to achieve the appointed needs of their study [50].

\subsection{Study Procedures}

Before carrying out the study, the researchers obtained approval from the Research Ethics Committee at KFU (REC REF Number: KFU-REC/2020-02-04). For FL classes, the researchers planned four sessions, with each one lasting 100 minutes. The first session was presented by both researchers; they clarified the nature of this study and introduced the FL model, e.g., its concept and process, to the students. They explained in detail how the teaching of the course would be done in the following three sessions. They discussed the type of FL materials and activities outside and inside the classroom.

Furthermore, the responsibilities of the course educator and the students were identified. The participants in the sample were informed about their rights, anonymity, and confidentiality. In this session, the students were divided into six groups based on their preferences. Each group comprised seven to eight students; each group was given a name related to social media, i.e., WhatsApp, Snapchat, Twitter, Instagram, Facebook, and Elmo. The three remaining sessions were presented by one researcher, who is the course instructor, to direct the students through group work and lead the discussion [51]. The fact that one of the researchers is the teacher of the students resulted in an advantage for the research due to the proximity of the researcher that able an active observation of student's reactions to the activities promoted. However, this restricted the study sample to the researcher students. The other researcher worked as an assistant educator inside the classroom. The application of the new teaching pedagogy was done through the following three steps:

\subsubsection{Step One}

Before FL classes, the session's materials and activities were designed by both researchers. The online materials 
included digital videos and PowerPoint presentations besides some supporting materials. According to Bergman and Sams[36], digital video has become a common technology format in classes that apply the FL model. The designed video lessons were short (five to ten minutes), informal, and attractive to put the students at ease and engage them $[25,36]$. The PowerPoint presentations were an explanation of the lesson content.

The online materials were particularly designed to promote kindergarten student teachers' SDL skills outside the classroom context [25]. The students were required to prepare for in-class activities by watching and studying the pre-provided content materials [38] (See Figure 1: step 1). The online materials were weekly uploaded to the students via the online platform "Blackboard" to enable the researchers to track the students' usage of online materials. In this regard, Shaalan[12] argued that online and technology resources, including language learning blogs, YouTube, documentaries, and Blackboard, are recommended to support the development of students' self-learning experiences. Furthermore, the researchers created a WhatsApp group to enable the students to share the given knowledge and information with their peers (See Figure 1: step 2). The WhatsApp group was also used to encourage students to view online materials. Regarding the in-class activities, they were varied, for example, dialogues, presentations, small group discussions, and further activities that focused on enhancing knowledge construction or higher-order thinking skills [52].

\subsubsection{Step Two}

The classroom was arranged in a way that facilitates group work; it was outfitted with chairs and small tables that were easily moved [8]. At each table, there were papers, pens, seven to eight small notebooks, and the activities handout/sheet. Each session lasted about 100 minutes; 10 minutes for a warm-up activity to refresh the students' memories, put them at ease, and remind them of the classroom rules, such as discussion and working collaboratively. Sixty to 100 minutes were allocated for face-to-face activities and discussion (See Table 1; See Figure 1: step 3); each activity ranged from 5 to 15 minutes. The remaining classroom time was assigned for self/peer assessment and answering students' questions. The type of in-class activity was varied between individual and group work. In this regard, Kim et al.[4] found that in FL classes, individual study or competitive study strategies can be employed. However, classes were usually organized in small groups to proceed with activities regarding study themes and practices.

\subsubsection{Step Three}

At the end of each session, the students were required to carry out a self/peer evaluation. They were also asked to fill in the session's evaluation sheet to be used for improving the next class (See Figure 1: step 4).

Table 1. A summary of the in-class activities

\begin{tabular}{|c|c|c|c|}
\hline \multirow{2}{*}{ Activity Number } & \multicolumn{3}{|c|}{ Activity Description } \\
\hline & Session 1 & Session 2 & Session 3 \\
\hline 1 & $\begin{array}{l}\text { Read, understand, and analyze an } \\
\text { image/picture }\end{array}$ & $\begin{array}{l}\text { Apply field experience to build } \\
\text { theoretical knowledge }\end{array}$ & Answer a question \\
\hline 2 & Answer a question & Answer a question & Answer a question \\
\hline 3 & Discuss an idea & $\begin{array}{c}\text { Discuss and exchange ideas } \\
\text { amongst the groups }\end{array}$ & Discuss an idea \\
\hline 4 & Answer a question & Answer a question & $\begin{array}{l}\text { Explain and interpret information } \\
\text { related to the activity provided }\end{array}$ \\
\hline 5 & Answer a question & Discuss and analyze a scheme & Discussion \\
\hline 6 & Summarize the information & $\begin{array}{l}\text { Read, understand, and analyze an } \\
\text { image/picture }\end{array}$ & Answer a question \\
\hline 7 & $\begin{array}{c}\text { Extract information from the } \\
\text { materials provided }\end{array}$ & Self/peer assessment & $\begin{array}{l}\text { Organize activity content into a } \\
\text { table }\end{array}$ \\
\hline 8 & $\begin{array}{l}\text { Organize information and ideas in } \\
\text { a mind map }\end{array}$ & & Dialogue and discussion \\
\hline 9 & Answer a question & & $\begin{array}{c}\text { Discussion } \\
\text { Answer a question } \\
\end{array}$ \\
\hline 10 & & & Present PowerPoint content \\
\hline
\end{tabular}




\subsection{Study Instrument: Development and Administration of the Questionnaires}

A structured questionnaire was used to collect the study data. The questionnaire was mostly developed based on validated questionnaires such as Fisher et al.'s [53] SDL readiness scale for nursing education and Ayyildiz and Tahran's[54] SDL skills scale for high school students. The questionnaire was a five-point Likert-type grading scale that was structured as strongly agree (5), agree (4), partially agree (3), disagree (2), and strongly disagree (1). To ensure the validity and reliability of the questionnaire, it was examined by eight faculty members at the College of Education. The questionnaire was then modified and piloted with 22 students who were not part of the study sample. They stated that the questionnaire items were clear and understandable. The student took from 10 to 15 minutes to fill out the questionnaire. The final version of the questionnaire consisted of 44 items $(\alpha=0.86)$ distributed across six main skills: seven items for planning $(\alpha=0.80)$, seven items for time management $(\alpha=0.83)$, eight items for critical thinking ( $\alpha=0.82$ ), eight items for research $(\alpha=0.83)$, seven items for information organization ( $\alpha=0.82)$, and seven items for self-evaluation $(\alpha=0.84)$. Cronbach's Alpha was greater than 0.07, which indicates that the questionnaire has a high reliability. During the experiment period, the study sample was asked to fill out the questionnaires twice. The first copy was filled out before the FL classes, whereas the second copy was filled out after they had completed the FL experience.

\subsection{Data Analysis}

To examine any differences in students' SDL skills, the researchers used the Statistical Package for Social Sciences (SPSS, version 23). The variables of the study were assessed twice: pre-FL classes and post-FL classes. Descriptive statistics, including frequencies, percentages, means, and standard deviations, were used. Analytical statistics such as a Pearson correlation analysis to determine the association between the questionnaire items and a paired t-test were also used to determine the differences between the pre-FL class and post-FL class means. The level of statistical significance was accepted at $p<0.05$ for all tests.

\section{Results}

The results of the two questionnaires are shown in Table 2.

The correlation between the scale items was highly positive, and the range of $\mathrm{r}$ between $0.737^{* *}(p<0.001)$ and $0.428 *(p<0.05)$. After the FL sessions, the study sample showed a statistically significant higher mean SDL $(4.51 \pm 0.13)$ compared to their score before the FL classes $(3.13 \pm 0.25)$ over three weeks. With regards to self-evaluation, (e.g., carry out an objective evaluation, goals achievement, effective study habits, identify strengthens and weaknesses, self-development, monitor expected to learn outcomes, and select appropriate strategies to achieve goals), students' initial mean score was the lowest $(2.98 \pm 0.41)$ compared to the mean scores of the other five skills. However, after the FL approach, the mean score increased $(M=4.50)$. The second lowest mean score related to time management skills such as efficient time distribution, short term planning, commitment to other individuals' time, time investment, managing priorities efficiently, the balance between personal and educational life, and monitoring time while performing tasks. The mean increased to 4.54 after the FL experience. Students' responses to items related to information organization skills (e.g., self-regulation, logical thinking, identify the appropriate alternative, interpret the problem, search for evidence to support thinking, accept new ideas, assess information and thoughts critically, and make decisions based on facts) showed an increase in the mean scores from $3.10 \pm 0.35$ to $4.50 \pm 0.24$. This conclusion applies to the rest of the SDL skills (See Table 2 below). To summarize, this result revealed that FL pedagogy had a positive impact on developing the SDL skills of kindergarten pre-service teachers in the College of Education at KFU.

Table 2. Difference between pre-test and post-test among the students

\begin{tabular}{|c|c|c|c|c|}
\hline Scale (mean+SD) & Pre-test & Post-test & $\mathrm{t}$ \\
\hline Planning & $3.19+0.32$ & $4.52+0.21$ & 34.097 & 19.445 \\
\hline Time management & $3.07+0.43$ & $4.54+0.28$ & 38.229 & $0.000^{* * *}$ \\
\hline Critical thinking & $3.18+0.27$ & $4.53+0.23$ & $0.000^{* * *}$ \\
\hline Research & $3.23+0.38$ & $4.49+0.26$ & 3.476 & $0.000^{* * *}$ \\
\hline Information organization & $3.10+0.35$ & $4.50+0.24$ & 25.733 \\
\hline Self-evaluation & $2.98+0.41$ & $4.50+0.31$ & $0.000^{* * *}$ \\
\hline Total & $3.13+0.25$ & $4.51+0.13$ & 43.547 \\
\hline
\end{tabular}

$* * * p<0.0001$ 


\section{Discussion}

As has been observed recently, FL has arisen worldwide as a promising pedagogy approach. Researchers found its significance in developing creativity, critical analytical skills, higher-order thinking skills, communication skills, collaboration abilities, and self-efficacy skills $[4,34,35,42,45,46]$. FL further significantly affect students' academic achievement, learning performance, motivation, independent learning, and SDL [6,25,46,47].

This study examined the effect of FL on the development of the SDL skills of kindergarten pre-service teachers. The results indicated that FL pedagogy has a positive impact on students' SDL skills identified in this study, including planning, time management, critical thinking, research, information organization, and self-evaluation. This result is in line with the findings of Zainuddin et al.'s[25] qualitative study that concluded that the FL class had improved students' SDL skills such as note-taking, self-evaluation, and self-regulation. The study participants further acknowledged that the FL model offered them great opportunities for monitoring learning activities, to assess their own performance as well as that of their classmates, and to recognize their weaknesses compared to others. Similar results were reported by Zainuddin and Perera[6], in which the participants claimed that the FL approach has significantly fostered their SDL abilities. FL enabled them to evaluate their learning needs, to direct their learning, to provide constructive feedback, to engage in peer-evaluation, and to think critically. These findings match Kim et al.'s.[4], Kan et al.'s[55], and Lee and Kim's[47] findings, which were that the FL technique has improved students' SDL skills. By contrast, Sirakaya and Ozdemir's[23] empirical study concluded that the FL model did not affect students' SDL readiness. They ascribed this to the characteristics of the study sample, as they already had a high level of learning readiness. These findings suggest that students' motivation would empower students to increase their SDL level [12,56].

On the one hand, the relationship between FL and SDL can be understood in light of the FL framework adopted in the current study. For instance, pre-class activities such as watching videos, PowerPoint presentations, and supplementary materials uploaded through the Blackboard platform are likely to stimulate students' SDL skills such as planning, time management, and information organization skills. In this respect, students would feel able to access course content anywhere, anytime, at the pace that is most convenient for them [6]. This process would empower them to plan their learning needs and goals, select appropriate learning resources, materials, and strategies, and improve independent note-taking [25,57]. Furthermore, sharing the given information or knowledge before class is likely to encourage students' thinking skills through exchanging their information, notes, questions, and thoughts. This step further would allow students to reflect on their and their peers' understanding of the course content. For the face-to-face phases, students are expected to apply learning materials and resources in in-class activities such as problem-solving, group work, and self/peer assessment. These processes would encourage students to activate skills such as monitoring and evaluation. In FL classes, a large part of monitoring themselves and group learning will be left to the student. They will be responsible for monitoring their own progress as well as that of their peers. They are further responsible for seeking assistance from instructors or classmates and for seeking resources to improve their learning situation as needed [58] (p. 35).

On the other hand, the linkage between FL and SDL may be referred to as the integration of technology. Videos and PowerPoint presentations would work better than traditional lectures as they are in line with the preferences of the new generation. The use of these technologies in education has become unavoidable because students extensively use the Internet and technology in their everyday lives [23]. Thus, they are likely to accept the new pedagogy, be motivated to engage with it, and to take advantage of it. Moreover, in FL classes, the use of technology and diversity in outside/inside learning activities would create an enjoyable and attractive learning environment that would increase students' participation and enjoyment of their learning [40]. To conclude, the results of this study argue that the FL model has the potential to develop the SDL skills of student teachers majoring in Kindergarten. Thus, the researchers recommend the integration of FL pedagogy in teaching in the Kindergarten Department. Furthermore, the Blackboard systems that are available in most Saudi higher education institutions are recommended (for teacher educators in kindergarten teacher preparation programs) as well as other higher education programs to offer students opportunities to practice SDL [12].

\section{Conclusions}

In the 21st century, changes in technology have affected different aspects of life worldwide, including education, in which student and teacher roles have been reversed. In light of this, the educators' role shifts to that of being a facilitator of learning instead of being the main source of learning. Meanwhile, it is now required of students to actively participate in learning processes, to take responsibility for their learning, to control their learning processes, and to create a student-oriented class environment [23]. In short, students are required to be self-directed learners. The results of the current study proved the positive contribution of applying FL pedagogy on enhancing the SDL skills of student teachers. Our results further support other literature that indicates the positive impact of the FL model on SDL skills. Thus, 
further follow-up experimental and mixed methods research is recommended in this field of study.

\subsection{Limitations and Future Research}

The current study has several limitations that should be taken into account in future studies. The first limitation is the purposive sample, and thus, the results cannot be generalized to other contexts or even other courses, departments, or colleges [49] at KFU. Therefore, we suggest that the study is replicated with control groups at KFU in such a way that the results can be generalized in this institution to enable SDL for all students. Furthermore, to contribute to the value researched in this study, a follow-up study that is driven from this one should be conducted. The sample should be more comprehensive and diverged through different educational institutions.

Further comparative studies in this thematic should be carried out, including comparison with other Saudi or Arabic higher education institutions that do not utilize this method and one that utilizes it. Also, international comparison studies should be recommended to enrich studies in this field. Secondly, the students engaged in this study were taught by one of the researchers. Thus, they might have provided untrue answers [23] to satisfy the course instructor. Furthermore, the results of this study highlighted the effectiveness of the FL model on developing students' SDL abilities. However, it did not explain how FL promoted student teachers' SDL. Hence, further follow-up mixed methods research is suggested to understand the positive relationship between FL and SDL skills. Mixed methods research with adequate design would be a significant contribution of the research field in education and pedagogy.

\section{REFERENCES}

[1] M. Gibbons. The self-directed learning handbook: Challenging adolescent students to excel, Jossey-Bass, San Francisco, 2002.

[2] M. Knowles. Self directed learning: A guide for learners and teachers, Chicago, IL: Follet, 1975.

[3] S. Jiusto, D. Dibiasio. Experiential learning Environments: Do they prepare our students to be self-directed, life-long learners?, Journal of Engineering Education, Vol.95, No.3, 195-204, 2006.

[4] S. Kim, N. Park, K. Joo. Effects of flipped classroom based on smart learning on self-directed and collaborative learning, International Journal of Control and Automation, Vol.7, No.12, 69-80, 2014.

[5] J. Rutkowski, K. Moscinska. Self-directed learning and flip teaching. Electric circuit theory case study, The 41st SEFI Conference, 16-20 September 2013, Leuven, Belgium, 2013.
[6] Z. Zainuddin, C. Perera. Supporting students' self-directed learning in the flipped classroom through the LMS TES BlendSpace, On the Horizon, Vol.26, No.4, 281-290, 2018.

[7] F. Wang. An exploration of online behaviour engagement and achievement in flipped classroom supported by learning management system, Computers \& Education, Vol.114, 79-91, 2017.

[8] M. Schlairet, R. Green, M. Benton. The flipped classroom strategies for an undergraduate nursing course, Nurse Educator, Vol.39, No.6, 321-325, 2014.

[9] S. Du, Z. Fu, Y. Wang. The flipped classroom - advantages and challenges, International Conference on Economic Management and Trade Cooperation (EMTC 2014), 17-20, 2014.

[10] S. H. Alwasal, S. M. Alhadlaq. Preparing middle eastern students for the future. In J. E. Groccia, M. A. Alsudairi, W. Buskist (Eds.), Handbook of college and university teaching: A global perspective, pp. 77-90, Sage Publication, New York, 2012.

[11] M. Khodary. Edmodo use to develop Saudi EFL students' self-directed learning, English Language Teaching, Vol.10, No.2, 123-135, 2017.

[12] I. Shaalan. Remodeling teachers' and students' roles in self-directed learning environments: The case of Saudi context, Journal of Language Teaching and Research, Vol.10, No.3, 594-556, 2019.

[13] T. Elyas, A. Alsadi. Critiquing of higher education policy in Saudi Arabia: A neoliberalism approach, The Asian Conference on Language Learning, Official Conference Proceedings, Osaka, Japan, 53-63, 2013.

[14] A. K. Hamdan. The road to culturally relevant pedagogy: Expatriate teachers' pedagogical practices in the cultural context of Saudi Arabian higher education, McGill Journal of Education, Vol.49, No.1, 201-226, 2014.

[15] K. B. Yusuff. Does self-reflection and peer-assessment improve Saudi pharmacy students' academic performance and metacognitive skills?, Saudi Pharmaceutical Journal, Vol.23, 266-275, 2015

[16] National Commission for Academic Accreditation and Assessment (NCAAA). Handbook for Quality Assurance and Accreditation; Saudi Arabia Part 3, Version 3, Muharram 1437H, NCAAA, 2016.

[17] World Bank. The road not traveled education reforms in MENA Washington DC, US.2017

[18] M. Soliman, G. Al-Shaikh. Readiness for self-directed learning among first year Saudi medical students: A descriptive study. Pakistan Journal of Medical Sciences, Vol.31, No.4, 799-802, 2015.

[19] H. Alkorashy, N. AbuAssi.) Readiness for self-directed learning among bachelor nursing students in Saudi Arabia: A survey-based study, International Journal of Nursing Education and Research, Vol.4, No.2, 187-194, 2016.

[20] M. Alsufyani, A. Aboshaigh, M. Moussa, O. Baker, K. Almalki. Competence of nurses relating self-directed learning in Saudi Arabia: A meta-analysis, Global Journal of Health Science, Vol.11, No.9, 145-152, 2019. 
[21] Y. Alrashid. Attitudes of students of the preparatory year at the University of Dammam towards self-directed learning, Journal of the College of Education - Port Said University, Vol.22, 262-294, 2017.

[22] F. AlHarbi. The effectiveness of the use of the flipped learning strategy in the development of self-learning skills and organizing the enrichment environment as perceived by gifted students, AL Manhal Collections, Vol.4, No.16, 2017. Online available fromhttps://platform.almnhal.com/Details/ Article/98563.

[23] D. Sirakaya, S. Ozdemir. The effect of a flipped classroom model on academic achievement, self-directed learning readiness, motivation and retention. Malaysian Online Journal of Educational Technology, Vol.6, No.1, 76-91, 2018.

[24] S. Boyer, D. Edmondson, A. Artis, D. Fleming. Self-directed learning: A tool for lifelong learning. Journal of Marketing Education, Vol.36, No.1, 20-32, 2014.

[25] Z. Zainuddin, H. Rahim, S. Muluk, C. Keumala. How do students become self-directed learners in the EFL flipped-class pedagogy? A study in higher education, Indonesian Journal of Applied Linguistics, Vol.8, No.3, 678-690, 2019.

[26] D. M. Kaufman. Applying educational theory in practice. In P. Cantillon, L. Hutchinson, D. Wood (Eds), ABC of learning and teaching in medicine, pp. 1-4, BMJ Publishing Group Ltd, London, 2003. Online available from cdn.mednet.co.il

[27] N. Hamdan, P. McKnight, K. McKnight, K. M. Arfstrom. A review of flipped learning, Online available from http://www. flippedlearning.org/review

[28] D. R. Edmondson, S. L. Boyer, A. B. Artis. Self-directed learning: A meta-analytic review of adult learning constructs, International Journal of Education Research, Vol.7, No.1, 40-84, 2012.

[29] D. R. Garrison. Self-directed learning: toward a comprehensive model, Adult Education Quarterly, Vol.48, No.1, 18-33, 1997.

[30] W. Kicken, S. Brand-Gruwel, J. van Merriënboer, W. Slot. Design and evaluation of a development portfolio: how to improve students' self-directed learning skills, Instructional Science, Vol.37, 453-473, 2009.

[31] T. Levett-Jones. Self-directed learning: Implications and limitations for undergraduate nursing education, Nurse Education Today, Vol.25, No. 5,363-368, 2005

[32] G. Borich. Effective teaching methods: Researched-based practice, 8th edn, Person, Boston, 2014

[33] C. N. Gunawardena, M. S. McIsaac. Distance education. In D. Jonassen (Ed.), Handbook for research on educational communication and technology, pp. 355-396, Simon and Schuster, New York, 2003. Online available from books.google.com.sa

[34] M. T. Munir, S. Baroutian, B. R. Young, S. Carter. Flipped classroom with cooperative learning as a cornerstone, Education for Chemical Engineers, Vol.23, 25-33, 2018.

[35] C. K. Lo, K. F. Hew. A critical review of flipped classroom challenges in K-12 education: possible solutions and recommendations for future research, Research and Practice in Technology Enhanced Learning, Vol.12, No.4, 1-22, 2017.

[36] J. Bergman, A. Sams. Flip your classroom: Reach every class every day, International Society for Technology in Education, Washington, DC, 2012.

[37] S. Sengel. To flip or not to flip: comparative case study in higher education in Turkey, Computers in Human Behavior, Vol.64, 547-555, 2016.

[38] S. Sletten. Investigating flipped learning: student self-regulated learning, perceptions, and achievement in an introductory biology course, Journal of Science Education and Technology, Vol.26, 347-358, 2017.

[39] H. Mohamed, M. Lamia. Implementing flipped classroom that used an intelligent tutoring system into learning process, Computers \& Education, Vol.124, 62-76, 2018.

[40] A. Almodaires, G. Alayyar, T. Almsaud, F. Almutairi. The effectiveness of flipped learning: A quasi-experimental study of perceptions of Kuwaiti pre-service teachers, International Education Studies, Vol.12, No.1, 10-23, 2019.

[41] J. L. Bishop, M. A. Verleger. The flipped classroom: A survey of the research, 120th ASEE Annual Conference and Exposition, Atlanta, GA, American Society for Engineering Education, Paper ID \#6219, 2013.

[42] A. Roehl, S. L. Reddy, G. J. Shannon. The flipped classroom: an opportunity to engage millennial students through active learning, Journal of Family and Consumer Sciences, Vol.105, 44-49, 2013.

[43] M. Gilboy, S. Heinerichs, G. Pazzaglia. Enhancing student engagement using the flipped classroom, Journal of Nutrition Education and Behavior, Vol.47, No.1, 109-114, 2015.

[44] E. Millard. 5 reasons flipped classrooms work. University business.com. 2012. Online available fromhttp://www.univ ersitybusiness.com/article/5-reasons-flipped-classrooms-wo rk

[45] A. AlJaser. Effectiveness of Using Flipped Classroom Strategy in Academic Achievement and Self-Efficacy among Education Students of Princess Nourah bint Abdulrahman University, English Language Teaching, Vol.10, No.4, 67-77, 2017.

[46] A. Al-Zahrani. From passive to active: The impact of the flipped classroom through social learning platforms on higher education students' creative thinking, British Journal of Educational Technology, Vol.4, No.6, 1133-1148, 2015.

[47] Y. Lee, H. Kim. Effect of flipped learning on self-directed learning and academic achievement in emergency medical technology students, The Korean Journal of Emergency Medical Services, Vol.20, No.2, 99-111, 2016.

[48] A. Sever, B. Oncul, A. Ersoy. Using Flipped Learning to Improve Scientific Research Skills of Teacher Candidates, Universal Journal of Educational Research, Vol. 7, No. 2, $521-535,2019$.

[49] L. Cohen, L. Manion, K. Morrison. Research methods in education (6th ed.), Routledge, London, 2007.

[50] C. Robson. Real world research: A resource for users of 
social research methods in applied settings (3rd ed.), Wiley-Blackwell, Cornwall, 2011.

[51] Y. Hao. Exploring undergraduates’ perspective and flipped learning readiness in their flipped classrooms, Computers in Human Behavior, Vol.59, 82-92, 2016.

[52] W. Slomanson. Blended learning: A flipped classroom experiment, Journal of Legal, Vol. 64, No.1, 93-102, 2014.

[53] M. Fisher, J. King, G. Tague. Development of a self-directed learning readiness scale for nursing education, Nurse Education Today, Vol.21, 516-525, 2001.

[54] Y. Ayyildiz, L. Tahran. Development of the self-directed learning skills scale, International Journal of Lifelong Education, Vol.34, No.6, 663-679, 2015.

[55] J. Kan, M. Shin, M. Kwon. The effect of project-based flipped learning model on self-directed learning ability, self-leadership and learning competency, Journal of Fisheries and Marine Sciences Education, Vol.82, No.5, 1478-1491, 2016.

[56] A. Boeve, R. Meijer, R. Bosker, J. Vugteveen, R. Hoekstra, C. Albers. Implementing the flipped classroom: an exploration of study behavior and student performance, Higher Education, Vol.74, 1015-1032, 2017.

[57] R. G. Brockett, R. Hiemstra. Self-direction in adult Learning: Perspectives on theory, research, and practice, Routledge, London and New York, 1991. Online available from books.google.com.

[58] L. Song, J. R. Hill. A conceptual model for understanding self-directed learning in online environments, Journal of Interactive Online Learning, Vol.6, 1, 2007. 